\title{
Intra-articular Injections for Osteoarthritis: From Bench to Bedside, can we Teach Old Drugs New Tricks?
}

\section{Paul YF Lee* and James Brock}

Welshbone, South Wales Orthopaedics Research Network, Wales, UK

"Corresponding author: Paul YF Lee, Welshbone, South Wales Orthopaedics Research Network, Wales, UK, Tel: +447764614688; E-mail: paul@welshbone.com

Rec date: June 28, 2016; Acc date: June 29, 2016; Pub date: June 30, 2016

Copyright: (C) 2016 Lee PYF, et al. This is an open-access article distributed under the terms of the Creative Commons Attribution License, which permits unrestricted use, distribution, and reproduction in any medium, provided the original author and source are credited.

Keywords: Osteoarthritis; Prolotherapy; Injections; Actovegin; Steroid; HA

\section{Introduction}

The two articles in this month's press of The Journal of Arthritis, one by Ekinci et al. titled 'A New Treatment Option in Osteoarthritis: Prolotherapy Injections' and the other by Senatorov et al. titled 'Clinical Outcome of Hylan G-F 20 Injections in Shoulder and Hip Osteoarthritis: A Retrospective Review' raise several important points surrounding the topic of intra-articular injections [1,2]. Firstly that there is a paucity of high quality literature in the field that often leads to inconclusive or misrepresented conclusions on drug efficacy in established treatments [1,2]. The articles also highlight the heterogeneity in injection procedure, site, concentration, preparation and outcome measurements $[1,2]$. This editorial will, therefore, provide a concise review on some of the current injection therapies and suggest possible improvements to methodological structure to inspire readers strive for high quality data. Further, through an example of a possible novel therapy, Actovegin, this editorial will hopefully challenge readers' way of thinking to consider the reapplication of established drugs; posing the question can you teach an old drug new tricks?

Cochrane review of 27 randomised control trials examining the effect of cortical steroid injections in Osteoarthritis reported an improved response to pain and function with cortical steroid treated patients when compared to placebo in smaller trials of low methodological quality and power with selected subgroups of patients [3]. On the other hand larger trials with more rigorous selection criteria demonstrated limited effect of cortical steroid at 6 weeks, questioning its efficacy [3]. Interestingly the Cochrane Musculoskeletal Group 2015 would consider cortical steroid to still be experimental in treating knee OA, they highlight two key issues for injection therapy.

The need of well-constructed, blinded, sham intervention/placebo controlled with adequately randomised and powered trials in established therapies [3]. Obviously in a clinical setting this is not always possible, yet for upcoming therapies there is a need to strive for this gold standard of research.

The effect in meta-analyses caused by the wide variety of preparations and dosage [3]. Should preparations such as Betamethasone, Dexamethasone, Prednisolone and Triamcinolone be evaluated under the same cortical steroid review? Certainly their efficacy should be assessed and considered individually and a dose response relationship calculated if any at all. Furthermore, most clinicians would mix a cortical steroid with different types of anaesthetic agents prior to injection; therefore their pharmacodynamics and pharmacokinetic property cannot be predicted.
Another popular substance used for injection therapy is Platelet Rich Plasma (PRP); the literature on PRP injections raises similar points. Of the 11 studies included in a Review by Simental-Mendíaa et al. across the board, all demonstrated safety and improvements in pain and function scores [4]. Further, in most cases when compared to Hyaluronic Acid (HA) preparations PRP showed superior improvements in pain and functional improvement in the treatment of OA [4]. Again studies included were generally case series of an unblinded or uncontrolled nature [4]. The point to highlight here again is that, PRP is highly dependent on the quality of patient's own blood growth factor concentrations and therefore no standardisation exists for randomised control trialling. Due to the large variation in patient global health and comorbidities, is it really possible to compare results of PRP use in OA?

Prolotherapy, as comprehensively covered by Ekinci et al. in this issue, is a combination of hypertonic dextrose, erythropoietin and local anaesthetic solutions [1]. Dextrose solutions above $10 \%$ act by inducing osmotic rupture of local cells and increase growth factors in the extracellular matrix [1]. This concise review article advocates the safe use of Prolotherapy injections and echoes our thoughts on the limitations of current literature by low power, poor quality study and variation in drug preparations [1]. Ekinci et al. fittingly suggest that future high quality research should elucidate the ideal strategy for Prolotherapy injection [1].

Intra-articular injection of HA as advocated through a retrospective case review by Senatorov et al. in this issue, here demonstrates the importance of case series data as a guide for future prospective clinical trials that could validate their conclusions [2]. The retrospective review of 26 subjects undergoing Hylan G-F 20 eloquently demonstrated safety and efficacy; adding clinical evidence to the hypothesis that HA can be effective in patients with end stage osteoarthritis [2].

Further research could review the effects of drugs like Botulinum neurotoxin A or cell injection therapies of Mesenchymal Stromal Cells (MSCs) or bring promising novel therapies such as Recombinant Human Fibroblastic Growth Factor (Rh FGF-18) or Transforming Growth Factor Beta (TGF- $\beta$ ) into the clinical setting through case series evaluation $[5,6]$. However, it is not just rigorous study of already establish treatments that is needed; there is also the need to identify novel therapies. One method of doing this would be to identify an already effective treatment in another area of musculoskeletal research, isolate its mechanism of action and apply this to the mechanisms of osteoarthritis. Thereby asking the question; can we teach an old drug new tricks?

Actovegin is a drug with 50 years of clinical history; it enhances aerobic oxidation in mammals, improving the absorption of glucose and oxygen uptake in tissue. It has been shown in in vitro models to 
Citation: Lee PYF, Brock J (2016) Intra-articular Injections for Osteoarthritis: From Bench to Bedside, can we Teach Old Drugs New Tricks?. J

Page 2 of 2

indirectly influence key players in the biochemical process of inflammation via CD68+ and repair via CD163+ macrophages [7]. Osteoarthritic synovial cells have been shown to express elevated levels of CD68+ markers [8]. Actovegin has been used in the treatment of acute muscle injuries, being show to improve clinical outcomes and reduce return to sport time in hamstring injuries of elite football players [9]. However, the in vitro evidence outlining the mechanism of action for Actovegin suggests it may have a role to be used in the treatment of osteoarthritis. Possibly this could be through an intraarticular injection. Further research here would look to review the mechanisms of Actovegin and apply this to the relevant Osteoarthritis evidence, possibly culminating in an experimental in vitro model. The next step following that would be a case series to judge primarily tolerance and safety, but at the same time to report any efficacy and improvements in clinical outcome. This exciting area of research could hopefully produce a realistic alternative to current therapies in a same vain highlighted by the review on Prolotherapy.

\section{Conclusions}

Intra-articular injections are an important final line of conservative intervention in a profession where maximising non-operative management is highly important. The current literature does demonstrate the need for high quality randomised controlled trialling for definitive conclusions on efficacy of established therapies. However, this issue of The Journal of Arthritis has highlighted the need for pioneering case series and review articles to demonstrate initial efficacy of promising therapies. Further, hopefully the example of Actovegin in this editorial will inspire readers to identify potential novel therapies. By looking to other branches of musculoskeletal injection therapy and applying established mechanisms of action to Osteoarthritis we hope readers will begin to ask the age old question; can you teach an old drug new tricks?

\section{References}

1. Ekinci S, Tatar O, Akpancar S, Turgut H, Seven MM (2016) A New Treatment Option in Osteoarthritis: Prolotherapy Injections. J Arthritis 5: 197.

2. Senatorov VV, Cuevas-Trisan R, Garcia FJ, Suciu GP, Parkes RH, et al (2016) Clinical Outcome of Hylan G-F 20 Injections in Shoulder and Hip Osteoarthritis: A Retrospective Review. J Arthritis 5: 200.

3. Jüni P, Hari R, Rutjes AW, Fischer R, Silletta MG, et al. (2015) Intraarticular corticosteroid for knee osteoarthritis. Cochrane Database Syst Rev.

4. Simental-Mendía MA, Vílchez-Cavazos JF, Martínez-Rodríguez HG (2015) Platelet-rich plasma in knee osteoarthritis treatment. Cir Cir 83: 352-358.

5. Kon E, Filardo G, Drobnic M, Madry H, Jelic M, et al. (2012) Non-surgical management of early knee osteoarthritis. Knee Surg Sports Traumatol Arthrosc 20: 436-449.

6. Roman-Blas JA, Bizzi E, Largo R, Migliore A, Herrero-Beaumont G (2016) An update on the up and coming therapies to treat Osteoarthritis, a multifaceted disease. Expert Opin Pharmacother.

7. Lee PYF (2012) The role of Actovegin in muscle injuries. Doctoral dissertation, Cardiff University, UK.

8. Benito MJ, Veale DJ, FitzGerald O, van den Berg WB, Bresnihan B (2005) Synovial tissue inflammation in early and late osteoarthritis. Ann Rheum Dis 64: 1263-1267.

9. Lee P, Rattenberry A, Connelly S, Nokes L (2011) Our experience on Actovegin, is it cutting edge?. Int J Sports Med 32: 237-241. 